\title{
FORMOWANIE SIE CHRZEŚCIJAŃSKICH OBRZĘDÓW MALŻEŃSKICH NA PODSTAWIE CARMEN XXV PAULINA Z NOLI
}

Chrześcijanie żyjący w pierwszych wiekach przez długi czas zachowywali wiele zwyczajów, obrzędów czy wręcz zabobonów, zarówno żydowskich, jak i pogańskich. Ojcowie Kościoła zwalczali te zaszłości i próbowali nadawać - zwłaszcza uroczystościom dotyczącym wydarzeń rodzinnych - coraz bardziej chrześcijański charakter, przywołując nauczanie biblijne. Jednym z takich obrzędów, które nazbyt długo nosiły charakter pogański, było wesele; nie tyle samo zawarcie związku sakramentalnego, co związane z nim różne pogańskie tradycje nie przystające chrześcijanom. Już w pismach Tertuliana spotykamy świadectwa, że w jego czasach do rzadkości należały śluby zawierane $\mathrm{w}$ kościele ${ }^{1}$. W niniejszym artykule zaprezentujemy bodajże jeden z pierwszych, jeśli nie pierwszy w ogóle opis konfrontujący pogański korowód weselny $z$ ukazaniem prawdziwej wartości chrześcijańskich małżeństw związanych sakramentalnie, łącznie z samymi uroczystościami weselnymi i strojami godnymi młodej pary chrześcijańskiej.

Paulin z Noli $(† 430)$ - teolog zapomniany, a wciąż aktualny ${ }^{2}$ - jest autorem 50 Listów, opublikowanych na życzenie jego przyjaciół, adresatów tych listów ${ }^{3}$, oraz 35 Pieśni (Carmina) i Epigramu dla Cynegiusza ${ }^{4}$. Po swym tzw.

\footnotetext{
* Ks. prof. dr hab. Jerzy Pałucki - kierownik Katedry Patrologii Greckiej i Łacińskiej w Instytucie Historii Kościoła i Patrologii na Wydziale Teologii Katolickiego Uniwersytetu Lubelskiego Jana Pawła II; e-mail: palucki@poczta.fm.

${ }^{1}$ Por. A.A. Bartnik, Matżeństwo w myśli Tertuliana. Ewolucja pogladów w okresie przedmontanistycznym i montanistcznym, Lublin 2015, 58 (mps Archiwum KUL).

${ }^{2}$ Por. J. Pałucki, Paulin z Noli. Zapomniany przez wieki, wzorem teologa na dzisiejsze czasy, w: Sprawiedliwość, pokój i radość w postugiwaniu biskupim. Księga pamiątkowa ku czci Jego Ekscelencji Księdza Biskupa dr Wiesława Alojzego Meringa z okazji 65. rocznicy urodzin, red. A. Niemira - K. Rulka - J. Szymański, Lublin 2010, 425: „Przede wszystkim był to chrześcijanin, asceta i pasterz, który w swym działaniu zawsze łączył contemplatio i actio”.

${ }^{3}$ Por. Paulinus Nolanus, Epistulae, ed. G. Santaniello, t. 1-2, Napoli - Roma 1992. Zob. J. Pałucki, Epistolografia w misyjnej posłudze Kościoła. Zagadnienia wybrane, SWł 17 (2015) 126: „Największy rozkwit listu patrystycznego przypada na tzw. złoty okres patrystyczny (325-451). Służyły szczególnie wzajemnemu wspieraniu się «nicejczyków» przeciw arianom i innym, wciąż powstającym herezjom.

${ }^{4}$ Por. Paulinus Nolanus, Carmina, ed. A. Ruggiero, t. 1-2, Napoli - Roma 1996.
} 
drugim nawróceniu (ascetycznym) osiadł z małżonką Terazją w Cimitile koło Noli, gdzie pozostał do śmierci w 431 r. Jego twórczość, choć ilościowo stosunkowo nieliczna, porównując np. z ilością pism św. Augustyna, jest jednak niezwykle głęboka teologicznie. Był najznamienitszym wówczas poetą obok Prudencjusza i Auzoniusza, mimo deklaracji, że wyrzeka się świata klasyki i swego doświadczenia literackiego. Dzieła jego są do dziś dnia wielkim wyzwaniem dla thumaczy i znawców, zarówno poetów, filologów klasycznych, jak i teologów. Jako mnich, a następnie biskup Noli, otaczał szczególną troską ludzi ubogich ${ }^{5}$. Jak pisze w Pieśni XXI, ubodzy są fundamentem jego domu ${ }^{6}$. Zachęca ludzi zamożnych, aby nie szczędzili swych dóbr materialnych dla tych, którzy cierpią niedostatek. Jako przykład do naśladowania podaje Pammachiusza ${ }^{7}$. Jan Paweł II w liście do Umberta Trammy, biskupa Noli, wskazał Paulina jako przykład człowieka, którego życie było podporządkowanie służbie Bożej i medytacji Słowa Bożego ${ }^{8}$. Swój talent poetycki połączony z doświadczeniem ascetycznym poświadczał codziennym życiem mnicha. Arystokratyczne pochodzenie i talent, a zarazem ascetyczny radykalizm Paulina, stanowiły wyjątek w ówczesnym imperium rzymskim 9 . W jego przypadku można mówić o początkach życia konsekrowanego w świecie.

W trakcie swej działalności duszpasterskiej, dostrzegając użyteczność osiągnięć kultury helleńsko-rzymskiej, mimo wcześniejszych deklaracji stopniowo coraz bardziej korzystał z umiejętności zdobytych wcześniej od swego mistrza Auzoniusza i utworzył nowy gatunek literacki - typowo chrześcijański, całkowicie oddany na służbę Chrystusowi oraz służący umacnianiu wiary czytelników ${ }^{10}$. Lektura Pieśni Paulina poświadcza, że korzystał praktycznie ze

${ }^{5}$ Por. J. Pałucki, Teologia w postudze pasterskiej Paulina z Noli, VoxP 34 (2014) t. 62, 428. Domenico Sorrentino (L'amore di unità: amicizia spirituale ed ecclesiologia in Paolino di Nola, „Impegno e Dialogo” 9:1991-1992, 160-166) określa teologię uprawianą przez Paulina jako „teologię życia", gdyż daje ona proste odpowiedzi na potrzeby i wątpliwości wiernych, por. tenże, Il cammino ascetico nel dialogo epistolare di Paolino, w: Mia sola arte è la fede: Paolino di Nola teologo sapienziale, a cura di L. Longobardo - D. Sorrentino, Napoli 2000, 97-150.

${ }^{6}$ Por. Paulinus Nolanus, Carmen XXI 391-394, ed. Ruggiero, t. 2, s. 38.

${ }^{7}$ Por. tenże, Epistula XIII 11, 9, ed. Santaniello, t. 1, s. 412: „Itaque patronos animarum nostrarum pauperes, qui tota Roma stipem meritant, multitudinem in aula apostoli congregasti”.

${ }^{8}$ Por. Joannes Paulus II, Lettera al vescovo di Nola Umberto Tramma, w: Insegnamenti di Giovanni Paolo II 18/1 (1995) 1293-1297; D. Sorrentino, La lettera di Giovanni Paolo II su Paolino di Nola . Commentario teologico-spirituale, „Teologia e Vita” 3 (1995) 13-35.

${ }^{9}$ Por. A. Ruggiero, Introduzione, w: Paolino di Nola, I Carmi, testo latino con introd., trad. italiana, note e indici a cura di A. Ruggiero, t. 1, Napoli - Roma 1996, 13: „Insieme con Prudenzio Paolino si pone al termine di una lunga esperienza poetica: in un ambiente il progetto poetico si integra nel progetto ascetico in conformità del ideale monastico, che si va affermando nelle clasi colte e aristocratiche".

${ }^{10}$ Por. F. George, The Difference God Makes. A Catholic Vision of Faith, Communion and Culture, New York 2009, 25: „The dialogue between faith and colture is called «inculturation of the faith» when a particular culture's symbols, institutions and values become vehicles for expressing the universal faith". 
wszystkich rodzajów literatury klasycznej, podejmując jednak wyraźnie tematy tylko teologiczne, często o charakterze typowo pastoralnym, nadając poezji zupełnie nowy chrześcijański charakter. Największą część Pieśni Paulin poświęcił św. Feliksowi - tzw. Carmina natalicia. Jedną pieśń tworzył prawie cały rok, stąd tak bogate słownictwo i głębia teologiczna. „Prapremiera” poszczególnych pieśni miała miejsce w uroczystość ku czci męczennika. Andrea Ruggiero zauważa, że od roku 409, kiedy to Paulin został biskupem Noli, siłą rzeczy zakończył się ten czas systematycznego, corocznego pisania Pieśni ku czci św. Feliksa. Powodów mogło być kilka: być może po prostu zaginęły lub też, co jest bardziej prawdopodobne, Paulin zaprzestał ich pisania, ponieważ musiał więcej czasu poświęcić pracy pastoralnej ${ }^{11}$. Przedmiotem Pieśni były np. opisy nowo wybudowanej świątyni, relacja o zadziwiającej ilości pielgrzymów przybywających do Cimitile, przedstawienie życia św. Feliksa i czynionych przez niego cudów. Często były to modlitwy dziękczynne za otrzymane łaski. Zdarzało się też, że impulsem do napisania nowej pieśni było przybycie znamienitych gości, którzy prosili Paulina o napisanie dzieła i pozostawali w Cimitile tak długo, aż ono powstało. Na przykład Pieśń XIII, która powstała w 407 r. przy okazji przebywania tam kilku arystokratów, którzy podjęli życie monastyczne, aby lepiej przygotować się do „prapremiery” odczytania, a raczej recytowania nowego dzieła przez Paulina. Zasadniczo Pieśni pisane były w języku łacińskim, ale zdarzało się także, że w czasie dorocznej uroczystości ku czci męczennika ten sam tekst Pieśni recytowany był także po grecku. Liturgia „odpustowa” była zawsze przygotowana z wielką starannością i stawała się pewnego rodzaju szkołą liturgiczną. Warto zaznaczyć, że Pieśni miały różny charakter, były one często bardzo doniosłe, innym razem pełne humoru, często zawierały pełne liryki opisy natury z uwzględnieniem fenomenu pobliskiego wulkanu Wezuwiusza. Paulin czuł się wolny w doborze tematu, choć ostatecznym celem było wychwalanie nadzwyczajności kultu św. Feliksa.

Zdarzały się także pieśni konsolacyjne. Były one zakorzenione w konsolacjach pogańskich, ale miały charakter głęboko eschatologiczny, napawający nadzieją. Przykładem takiej pieśni jest List do Pammachiusza, senatora rzymskiego, napisany po śmierci jego małżonki, znany jako List XIII. Powstawały także pieśni polemiczne, czego przykładem jest Pieśń XXX ${ }^{12}$, chociaż zdaniem znawców jest ona zwyczajnym listem napisanym $w$ dystychach elegijnych, a jej fragmenty odnaleźć można także w Liście XXXII do Sewera ${ }^{13}$. Thomas Lehmann zdecydowanie uważa, że pieśń ta nie jest autorstwa Paulina i powstała już po jego śmierci ${ }^{14}$.

${ }^{11}$ Por. Ruggiero, Introduzione, s. 22-23; G. Luongo, Lo specchio dell'agiografo. S. Felice nei carmi XV e XVI di Paolino di Nola, Napoli 1992, 46.

${ }^{12}$ Por. Paulinus Nolanus, Carmen XXX, ed. Ruggiero, t. 2, s. 326.

${ }^{13}$ Por. P. Fabre, Essai sur la chronologie de l'oeuvre de Saint Paulin de Nole, Paris 1948.

${ }^{14}$ Por. T. Lehmann, Eine spätantike Inschriftensammlung und der Besuch des Papstes Damasus an der Pilgerstatte des Hl. Felix in Cimitile/Nola, ZPE 91 (1992) 243-274. 
Do najpiękniejszych należy Pieśń XXV, przy której pisaniu Paulin korzystał z często stosowanego w świecie pogańskim rodzaju epitalamicznego, stąd też i jej nazwa Epithalamium - „Pieśń weselna”15. Znawcy poezji klasycznej i wczesnochrześcijańskiej, A. Ruggiero ${ }^{16}$ i Jacques Fontaine ${ }^{17}$ wskazują na wyraźne podobieństwo tej weselnej pieśni z dziełem Tertuliana De cultu feminarum ${ }^{18}$.

Trudno jest odnaleźć w literaturze patrystycznej opis zawierania chrześcijańskiego związku małżeńskiego. Jeszcze pod koniec IV w. bardzo rzadko znajdujemy takie opisy. Początkowo ta uroczystość odbywała się w domu pani młodej, nawet bez obecności kapłana. Biskupi zachęcali, aby jednak przedstawiciel prezbiterów był w trakcie zaślubin i zalecali, aby następnego dnia młodzi małżonkowie udawali się do świątyni na Eucharystię, by dziękować za dar zjednoczenia i prosić o potrzebne łaski. Tak więc w pierwszych wiekach zaślubiny chrześcijan były uroczystością rodzinną, a sama oprawa, w zależności od zamożności rodziny nowożeńców, była wystawna, niewiele różniąca się od podobnych uroczystości pogańskich. Zdecydowanie gani to Paulin, którego zaślubiny z Terazją miały, mimo ich zasobności materialnej, charakter bardzo skromny oraz przepełniony modlitwą i lekturą Pisma Świętego. Bez wątpienia miały one miejsce w świątyni i związek został pobłogosławiony przez biskupa Delfina z Marsylii, który nieco wcześniej ochrzcił Paulina.

Pieśn XXV - Epithalamium dedykowana została młodej parze, z która Paulin był zaprzyjaźniony, szczególnie z ojcem nowożeńca. Podobnie jak Pieśni XXXI i XVI ma ona charakter konsolacyjny, pełen barwnych opisów, zabawnych scen, ale i krytyki. W Epithalamium napisanym z okazji zaślubin Juliana i Tyzii, podobnie jak w dwu poprzednich przypadkach, Paulin korzysta ze znanej formy (distichi elegiaci), nadając jednak utworom charakter typowo chrześcijański. Zdarzenie miało miejsce przed rokiem 405/406, gdy Julian nie był jeszcze diakonem ${ }^{19}$. W przeciwnym razie nie mógłby zawrzeć związku małżeńskiego. Nie mogło to wydarzenie mieć miejsca także w latach 400/404 gdyż biskup Emiliusz, który błogosławił związek małżeński, przebywał wówczas w Konstantynopolu. Tak więc mogło się ono zdarzyć w czasie drogi powrotnej biskupa Emiliusza z Konstantynopola.

Utwór, oprócz charakteru pewnej ,laurki” dla młodzieńców”, miał też znaczenie dydaktyczne. Paulin był świadkiem zaślubin wielu chrześcijan, których wesela nie różniły się zbytnio od pogańskich. W pierwszym wersecie przedstawia adresatów. Są to: dobrze wychowany syn biskupa oraz dziewica bardzo

${ }^{15}$ Por. Plezia II 347.

${ }^{16}$ Por. Ruggiero, Introduzione, t. 1, 32.

${ }^{17}$ Por. J. Fontaine, Les symbolismes de la cithare dans la poésie de Paulin de Nole, w: Romanitas et Christianitas. Studia J.H. Waszink oblata, ed. W. den Boer - P.G. van der Nat - C.M.J. Sicking - J.C.M. van Winden, Amsterdam 1973, 123-143.

${ }^{18}$ Por. opracowanie Tertulianowej teologii małżeństwa: Bartnik, Małżeństwo w myśli Tertuliana. Ewolucja pogladów w okresie przedmontanistycznym i montanistycznym.

${ }^{19}$ Choć Julian w tekście bywa określany jako clericus, to jednak chodziło z całą pewnością o lektorat. 
ceniona $\mathrm{w}$ swoim środowisku ${ }^{20}$. Paulin ukazuje ich nieskazitelne charaktery i wskazuje na jedyny motyw tego związku, a mianowicie miłość i wspólną wiarę ${ }^{21}$. Podkreśla także ich czystość przedmałżeńską, co w związkach pogańskich, a często i chrześcijańskich, nie było doceniane. Zaznacza, że tym razem zarówno młoda para, jak i zaproszeni goście, nie dali się uwieść pogańskim bóstwom miłości, szczególnie Wenerze i jej synowi Kupidynowi. Jak się dalej okazuje, Tyzia pochodziła z rodu kapłańskiego, co zapewniać jej miało nieskazitelność życia moralnego. Nolańczyk podaje definicję chrześcijańskiej miłości małżeńskiej: „Zgodny związek małżeński jest bowiem umiłowaniem pobożności, a zarazem uczciwością w miłości i pokojem z Bogiem"22. Paulin przywołuje biblijny opis stworzenia Ewy z żebra Adama, aby ukazać, że małżonkowie rzeczywiście z woli Bożej mają być jednym ciałem, przy zachowaniu odrębności i wolności osobowej. Ewa nie jest jako część ciała Adama jemu poddana, lecz jest jego towarzyszką życia ${ }^{23}$.

Po wyjaśnieniu wiernym teologicznej głębi duchowej związku małżeńskiego Paulin przystępuje do pochwał, dotyczących sposobu urządzenia uroczystości zawarcia małżeństwa: uczty weselnej, strojów młodej pary, sposobu ich zachowania. Jest to, jak wyżej wspomniano, najprawdopodobniej pierwszy taki opis zaślubin chrześcijańskich. Paulin zachęca młodą pannę wydawaną za osobę konsekrowaną, aby wyrzekła się niegodnego, nieprzystającego chrześcijance stroju. Zaleca, aby nie używała makijażu, drogich perfum, skąpego, niemal transparentnego stroju, jak to czyni wiele panien. Wyśmiewa sztuczne warkocze, a szczególnie „syntetyczne” uwypuklanie swych wdzięków cielesnych, które miałyby przyciagać uwagę narzeczonego i gości. Paulin poucza, że sposób zachowania zarówno nowożeńców jak i zaproszonych gości ma być niejako „dzwonem”, przyciągającym przechodniów i obserwatorów do Chrystusa $^{24}$. Istniał wówczas zwyczaj przyozdabiania drzwi stosownymi ozdobami. Przygotowywano trasę pochodu weselnego, czyniąc na ulicy dywany z żywych kwiatów, ukazujące różne, nie zawsze przystojne sceny, układane np. z płatków róż i najdroższych kwiatów. Nolańczyk zdecydowanie wzywa, aby chrześcijański orszak weselny nie był zeszpecony ozdobami uwłaczającymi

${ }^{20}$ Por. Paulinus Nolanus, Carmen XXV 1, ed. Ruggiero, t. 2, s. 182: „Concordes animae casto sociantur amore, / virgo puer Christi, virgo puella dei”. Warto dodać, że ojciec pana młodego był wówczas cenionym biskupem miasta Kapui.

${ }^{21}$ Por. D. Kasprzak, Il pensiero sociale di Paolino da Nola, SL 2, Supl. 1, Kraków - Oborniki Śląskie 2002, 113-122 i 144-147. Autor, komentując rozważania Paulina o małżeństwie, zauważa, że dzięki syntezie trzech wątków - moralnego napomnienia, kwestii jurydycznej oraz perspektywy teologicznej - biskup Noli nie sprowadza małżeństwa jedynie do więzi prawnej, ale jest ono wypełnieniem ludzkiej miłości w świętości, uczciwości i pokoju, zgodnie z wolą Bożą.

${ }^{22}$ Por. Paulinus Nolanus, Carmen XXV 13-14, ed. Ruggiero, t. 2, s. 184: „Nam pietatis amor simul est et amoris honestas / paxque deo concors copula coniugii”, thum. własne.

${ }^{23}$ Por. tamże XXV 19, ed. Ruggiero, t. 2, s. 184: „Nam sopitus Adam costa privatus adempta est / moxque suo factam sumpsit ab osse parem".

${ }^{24}$ Por. tamże XXV 30, ed. Ruggiero, t. 2, s. 184: „Christus ubique pii voce sonet populi”. 
świętym ${ }^{25}$. Istniał wówczas, jak już wspomniano, zwyczaj rozlewania na ulicach cennych olejków wydających piękny zapach. Także ta praktyka, zdaniem Paulina, nie jest godna chrześcijańskiego orszaku weselnego. Jak pisze, jedyną wonią godną świętych powinno być świadectwo dawane Chrystusowi i jego nauczaniu, czyli to, co ofiaruje im sam Bóg ${ }^{26}$. Chrześcijanie mają obowiązek rozsiewać woń Chrystusa nie ziemskim bogactwem waz pełnych pachnących olejków, ale godnością i czystością obyczajów. Ozdobą narzeczonej z tak świętej rodziny ma być nie bogactwo stroju i klejnoty. Motyw jest bardzo prosty: to nie stroje i bogate przyjęcia są okazją do ukazania prawdziwego dobrobytu, ale narzeczona, pełna cnót staje się prawdziwym klejnotem w oczach Pana ${ }^{27}$. Ma ona być ozdobiona darami Ducha Świętego. W przeciwnym razie stanie się jedynie obiektem pożądania. Dla gości płci męskiej, a także dla samego nowożeńca, mogą stać się ważniejsze przyozdabiające ją klejnoty i ozdobna oprawa uczty weselnej, niż sama panna młoda. Dlatego Paulin zaleca, aby chrześcijanka nie nakładała wymyślnych szat, nie farbowała warkocza na te okazję, ani nie malowała oczu ${ }^{28}$.

Paulin wielokrotnie zachęca, wręcz zaleca, aby chrześcijańska narzeczona nie naśladowała pogańskich obyczajów weselnych ${ }^{29}$. To, co światowe, jest znakiem ciemności. Próżna pycha nie ma nic wspólnego z dostojeństwem, a świętość nie może podążać w cieniu mroków pogaństwa ${ }^{30}$. Paulin szczególne krytykuje tańce, przywołując przykład Herodiady ${ }^{31}$. Podobne rady kieruje także do nowożeńca. Przypominając mu o jego godności i obowiązkach jako lektora (w owym czasie), upomina, aby nie zwracał uwagi na wygląd zewnętrzny, nie stroił się nieprzyzwoicie, chociaż go na to stać, lecz aby pamiętał, że to sam Chrystus przyozdabia go w to, co najcenniejsze ${ }^{32}$.

Paulin przypomina obojgu, że jednakowo zostali przez Chrystusa przyozdobieni tym, co najważniejsze i nieprzemijające: nadzieją pobożnością, wiara, pokojem, skromnością (spe pietate fide pace pudicitia) ${ }^{33}$. Wylicza kolejno najcenniejsze dary, w które powinni być przystrojeni nowożeńcy.

${ }^{25}$ Por. tamże XXV 31-34, ed. Ruggiero, t. 2, s. 184: „Nulla per ornatas insultet turba plateas; / nemo solum foliis, limina fronde tegat, / nec sit Christicolam fanatica pompa per urbem;/ nolo profana pios polluat ambitio".

${ }^{26}$ Por. tamże XXV 30, ed. Ruggiero, t. 2, s. 184.

${ }^{27}$ Por. tamże XXV 45, ed. Ruggiero, t. 2, s. 184: „Respuat et variis distincta monilia gemmis, / nobilis ut domino gemma sit ipsa deo".

${ }^{28}$ Por. tamże XXV 63, ed. Ruggiero, t. 2, s. 186: „,non fucis male ficta cutem neque lumina nigro / pulvere nec flavo tincta colore comam".

${ }^{29}$ Por. tamże XXV 83, ed. Ruggiero, t. 2, s. 188: „Tu neque odoratis vaga vestibus atque capillis / naribus agnosci, qua gradiare, velis".

${ }^{30}$ Por. tamże XXV 139-149, ed. Ruggiero, t. 2, s. 192.

${ }^{31}$ Por. tamże XXV 120-135, ed. Ruggiero, t. 2, s. 190.

${ }^{32}$ Por. tamże XXV 93, ed. Ruggiero, t. 2, s. 188: „Conpensavit enim Christus tibi largiter ornans / perpetuis pulchram divitiis animam".

${ }^{33}$ Por. tamże XXV 96, ed. Ruggiero, t. 2, s. 188. 
Stwierdza mianowicie, że prawdziwym srebrem, które ich przyozdabia, jest Słowo Boże (Sermo Dei argentum est), a złotem - Duch Święty ze swymi darami (Sanctus Spiritus aurum); natomiast pełnego splendoru dodają im dobre dzieła, które są dla nich prawdziwymi klejnotami (mentibus et gemmae clara bonorum operum $)^{34}$. Jako doskonały znawca Pisma Starego i Nowego Testamentu Paulin dobrze rozumie prawdziwe piękno narzeczonej, które pochodzi z wnętrza człowieka, i jako wzór do naśladowania podaje przykład Rebeki, udającej się na spotkanie swego przyszłego małżonka. Mimo zasobności jej ojca i możliwości przyozdobienia się w najdroższe stroje i klejnoty, okryta była tym, co najcenniejsze - skromnością $(\text { pudor })^{35}$.

Przechodząc do głębszego omówienia stawianych przez siebie wymagań Paulin wyjaśnia, że młodzieniec, doskonale znający teksty Pisma Świętego, zdawał sobie sprawę, iż całe piękno jego przyszłej żony to nie jej uroda fizyczna, ani piękne szaty, ale „strój” który otrzymuje od Chrystusa. Ona została przygotowana przez Pana, aby, jako dar boży pomagała mężowi. Ta współpraca ma doprowadzić do tego, że pewnego dnia małżonka, wspierająca wiarą swojego męża, sprawi, że ich jedność stanie się nie tylko jednym ciałem świętych, ale dla obydwojga Chrystus stanie się Głową ${ }^{36}$. Po podaniu wielu przykładów kobiet, które odegrały istotne znaczenie w historii zbawienia, poczynając od niechlubnej roli Ewy, podaje jako ukoronowanie przykład Maryi, która dodaje odwagi kobietom, bo to właśnie Ona została wybrana, aby dać ludzką naturę Synowi Bożemu dla zbawienia ludzkości ${ }^{37}$. Paulin natychmiast zaznacza, że Maryja była małżonką w momencie zrodzenia Zbawiciela, ale nie była żoną według ciała. Dalej wyjaśnia tajemnicę Kościoła i rolę w nim kobiety, wynikającą z faktu Wcielenia: Maryja stała się małżonką, lecz nie „dotkniętą” przez mężczyznę. To w pewien sposób dotyczy tajemnicy związku Kościoła i Chrystusa: Kościół jest zarazem małżonką, ale i siostrą Chrystusa, ponieważ nie został mu poddany ${ }^{38}$. Dostrzegamy tu ogromną rolę kobiety w życiu Kościoła i rodziny, poczynając od nieszczęsnej Ewy, a kończąc na chwalebnej roli Maryi, z której to Bóg wziął ciało dla swego Syna. Paulin poucza, że z tej samej Matki Syna Bożego, która stała się Matką narodów, pochodzą w równy sposób kobiety i mężczyźni. Co więcej, jak podkreśla Paulin, w Chrystusie nie ma już ani kobiety ani mężczyzny, ale ludzi łączy ta sama wiara i to samo ciało ${ }^{39}$. Zostaje przerwany tragizm pokoleń trwający od Adama, ponieważ ludzie maja

${ }^{34}$ Por. tamże XXV 97-98, ed. Ruggiero, t. 2, s. 188.

${ }^{35}$ Por. tamże XXV 107-108, ed. Ruggiero, t. 2, s. 188: „pulchra Rebecca sacrum cum sponsa veniret ad Isac, / simpliciter velo tecta pudoris erat".

${ }^{36}$ Por. tamże XXV 145-147, ed. Ruggiero, t. 2, s. 192.

${ }^{37}$ Por. tamże XXV 160-161, ed. Ruggiero, t. 2, s. 192: „quo deus adsumpsit virgine matre hominem. / O nova ad humanam domini commenta salutem!"

${ }^{38}$ Por. tamże XXV 167-169, ed. Ruggiero, t. 2, s. 194: ,grande sacramentum, quo nubit eclesia Christo / et simul est domini sponsa soror que sui. / Sponsa quasi coniunx, soror est, quia subdita non est".

${ }^{39}$ Por. tamże XXV 179-184, ed. Ruggiero, t. 2, s. 194: „Inde magister ait, quia iam nec femina 
teraz możliwość osiagania anielskiej piękności. Źródłem tej nadzwyczajnej łaski jest chrzest święty, dzięki któremu zarówno mężczyźni, jak i kobiety, otrzymują tę samą łaskę. Pod koniec Pieśni Paulin składa jakby w imieniu Chrystusa życzenia: „Przez pamięć na mnie żyjcie zawsze w nienaruszonym związku, niech waszą więzią będzie krzyż godny czci" ${ }^{40}$. To życzenie skierowane jest do wszystkich, aby skorzystali z chwili łaski, zwłaszcza, że drugim świadkiem sakramentu jest biskup będący ojcem pana młodego, choć z nieznanych do końca przyczyn to nie on, ale jego przyjaciel przewodniczy uroczystości ${ }^{41}$. Ostatecznie biskup Emiliusz proroczo życzy, aby cały ród towarzyszącego mu biskupa stał się swego rodzaju domem Araona ${ }^{42}$.

$* * *$

Epithalamium Paulina z Noli świadczy o dokładaniu przez biskupów ery wczesnochrześcijańskiej wielu starań, aby sakramenty sprawowane w świątyni miały godną oprawę, pełną głębokiej duchowej symboliki. Wiązało się to zapewne z utrzymywaniem się w społeczności chrześcijan praktyk weselnych zakorzenionych w pogańskiej obrzędowości, a także ze sposobem rozumienia samego sakramentu małżeństwa, odbiegającym od ewangelicznych wskazań. Biskup Noli, sam doświadczony małżonek, odwraca uwagę nowożeńców i uczestników uroczystości od spraw zewnętrznych i wskazuje prawdziwe bogactwa związku małżeńskiego, w postaci łask pochodzących od całej Trójcy, umożliwiających zdobywanie chrześcijańskich cnót, które stanowią prawdziwą ozdobę chrześcijanina. Paulinowy opis uroczystości małżeńskiej jest nie tylko cennym świadectwem historycznym, ale stanowi także przejaw jego duszpasterskiej troski o wiernych. Wnioski, do których dochodzi, obserwując niedojrzałe zachowania niektórych chrześcijan, oraz argumentacja teologiczna, która ma wskazać na to, co istotne w sakramencie małżeństwa, są wciąż aktualne, ponieważ - mimo upływu czasu - nie zmieniły się zbytnio sposoby świętowania największych tajemnic sakramentalnych, niejednokrotnie dalekie od ich duchowej istoty.

\footnotetext{
nec mas / in Christo, sed idem corpus et una fides. / Namque omnes unum corpus sumus, omnia Christo / membra quibus Christus corporis in caput est".

${ }^{40}$ Por. tamże XXV 191-192, ed. Ruggiero, t. 2, s. 194: „Ergo mei memores par inviolabile sem$\mathrm{per} /$ vivite; sit vobis crux veneranda iugum”, thum. własne.

${ }^{41}$ Por. tamże XXV 199, ed. Ruggiero, t. 2, s. 196: „Ipse pater vobis benedicat episcopus, ipse / praecinat hymnisonis cantica sancta choris".

${ }^{42}$ Por. tamże XXV 238, ed. Ruggiero, t. 2, s. 200: „et domus Aron sit tota domus Memoris”.
} 


\section{THE FORMATION OF CHRISTIAN RITES \\ OF THE SACRAMENT OF MARRIAGE \\ ACCORDING TO CARMEN XXV BY PAULINUS OF NOLA}

\section{(Summary)}

Church Fathers tried to combat the legacy of paganism and made tireless efforts towards Christianising family events, recalling the teaching of the Bible. Tertullian, for example, complained that the Christians of Carthage didn't marry in the church. The article discusses Carmen XXV of Paulinus of Nola ( $\uparrow 431)$, written for the occasion of marriage of Julian and Tysia. The poem contains one of the oldest descriptions of the ceremony of Christian marriage. Bishop of Nola pays attention to the spiritual dimension of the sacrament - specifically to its rich, full of symbols rite as well as to fact that the Christian meaning of the marriage ceremony should become the main focus for wedding preparations.

Key words: Paulinus of Nola, Carmen XXV, rites of the sacrament of marriage.

Słowa kluczowe: Paulin z Noli, Carmen XXV, obrzędy małżeńskie.

\section{BIBLIOGRAFIA}

\section{Źródła}

Paulinus Nolanus, Carmina, introd., trad. italiana, note e indici a cura di A. Ruggiero, t. 1-2, Napoli - Roma 1996.

Paulinus Nolanus, Epistulae, introd., note e indici a cura di G. Santaniello, t. 1-2, Napoli - Roma 1992.

\section{Opracowania}

BARTNIK A.A., Matżeństwo w myśli Tertuliana. Ewolucja pogladów w okresie przedmontanistycznym i montanistycznym, Lublin 2015 (mps Archiwum KUL).

Fabre P., Essai sur la chronologie de l'oeuvre de Saint Paulin de Nole, Paris 1948.

Fontaine J., Les symbolismes de la cithare dans la poésie de Paulin de Nole, w: Romanitas et Christianitas. Studia J.H. Waszink oblata, ed. W. den Boer - P.G. van der Nat - C.M.J. Sicking - J.C.M. van Winden, Amsterdam 1973, 123-143.

George F., The Difference God Makes. A Catholic Vision of Faith, Communion and Culture, New York 2009.

KasprzaK D., Il pensiero sociale di Paolino da Nola, SL 2, Supl. 1, Kraków - Oborniki Śląskie 2002.

Lehmann T., Eine spätantike Inschriftensammlung und der Besuch des Papstes Damasus an der Pilgerstatte des Hl. Felix in Cimitile/Nola, ZPE 91 (1992) 243-274.

Luongo G., Lo specchio dell'agiografo. S. Felice nei carmi XV e XVI di Paolino di Nola, Napoli 1992.

PAŁuCKI J., Epistolografia $w$ misyjnej postudze Kościoła. Zagadnienia wybrane, SW1 17 (2015) 121-132.

PaŁucki J., Teologia w postudze pasterskiej Paulina z Noli, VoxP 34 (2014) t. 62, 427-434.

PaŁucki J., Paulin z Noli. Zapomniany przez wieki, wzorem teologa na dzisiejsze czasy, 
w: Sprawiedliwość, pokój i radość w postugiwaniu biskupim. Księga pamiqutkowa ku czci Jego Ekscelencji Księdza Biskupa dr Wiesława Alojzego Meringa z okazji 65. rocznicy urodzin, red. A. Niemira - K. Rulka - J. Szymański, Lublin 2010, 419-428.

Ruggiero A., Introduzione, w: Paolino di Nola, I Carmi, testo latino con introd., trad. italiana, note e indici a cura di A. Ruggiero, t. 1, Napoli - Roma 1996, 13-77.

Sorrentino D., L'amore di unità: amicizia spirituale ed ecclesiologia in Paolino di Nola, „Impegno e Dialogo” 9 (1991-1992) 149-169.

Sorrentino D., Il cammino ascetico nel dialogo epistolare di Paolino, w: Mia sola arte è la fede: Paolino di Nola teologo sapienziale, a cura di L. Longobardo - D. Sorrentino, Napoli 2000, 97-150.

Sorrentino D., La lettera di Giovanni Paolo II su Paolino di Nola. Commentario teologico-spirituale, „Teologia e Vita” 3 (1995) 13-35. 